\title{
Land Types and Sustainable Cocoa Production: Lessons from GIS Application
}

\author{
O. Pabi \\ Remote Sensing Application Laboratory, Department of Geography and Resource Development, $P$. \\ O. Box LG 59, University of Ghana, Legon, Accra \\ E-mail:opabi@yahoo.com
}

\begin{abstract}
Sustainable cocoa production demands a range of biophysical conditions of land. The paper reports on the levels of sustainability of cocoa production on different soil types under different tree cover intensities. Geographic Information System (GIS) analytical functionalities were extensively applied in the study. The spatial distribution of cocoa was modeled from geo-located samples, and related to tree cover generated from Landsat ETM+ image for 2000 and soils types. There was a strong spatial association between cocoa density-distribution surface, soil types and tree cover. It was observed that soils that are naturally suitable for cocoa were still supporting extensive cocoa farms, whereas unsuitable lands that were initially cultivated with cocoa had only remnant or no cocoa farms. The outcome of this study indicates that decisions for cocoa cultivation should be informed by accurate information on the suitability of lands for sustainable production.
\end{abstract}

\section{Introduction}

Sustainable agriculture seeks to guide the application of prior experience and the latest scientific advances to create integrated, resource-conserving and equitable farming systems which reduce environmental degradation, maintain agricultural productivity, promote economic viability in both the short and long term, and maintain stable rural communities and quality of life (Francis \& Youngberg, 1990; Smyth \& Dumanski, 1993).

Current global cocoa production is concentrated in West Africa, where La Cote d'Ivoire and Ghana contribute about 60\% (Blackwell, 2007). Despite the large share of cocoa in national incomes, producing countries have been characterized by slow agricultural growth, poverty, falling wages, and stagnant economies. In Ghana, farmers have cultivated cocoa over the years with mixed outcome. In some cases, yield has been drastically reduced, with attendant negative effect on the quality of farmers' life. Land and environmental resources have also experienced attendant negative impacts such as plant and animal diversity loss, deforestation and soil degradation (Attua \& Laing, 2003).

Presumably, when cocoa was initially introduced in Ghana, farmers had no knowledge and experience of the long-term performance of cocoa on various land types. They established cocoa farms wherever forested land was available. In a study of the Western Region of Ghana, an important cocoa frontier, Benneh (1988) indicated that most cocoa farms failed because they were cultivated on soils that were unsuitable for cocoa. Similar developments have been found in Nigeria (Fasina et al., 2007 ), and the Manya Krobo District in Ghana (Amanor, 1994).

The New Juabeng area is one of the earlier important frontiers of cocoa production in Ghana. However, specific localities have experienced significant decline in cocoa production. Even though some areas have been replanted, the success rate has been spatially variable (Adu \& Asiamah, 1992). A good knowledge of factors that engender this differential success rates could inform the decision-making for sustainable cocoa production management systems.

Prioritizing appropriate mix of relevant production factors will guarantee sustainable production and protection of the biophysical supporting systems. The choice of suitable soil types is an important element of this mix of factors (Fasina et al., 2007). The application of the concept of land suitability is an important agricultural production strategy that seeks to achieve the dual objectives of optimizing crop production and minimizing environmental damage. Thus, effective application of the suitability concept could effectively balance the complex issues of improved crop 
production, environmental protection and market demand satisfaction for sustainable cocoa production.

Current technological developments present opportunities to innovative research approaches that enhance the generation of required information for production management decisions for sustainable agricultural production. The study sought to provide information to inform decisions on land resource allocation for sustainable cocoa production and environmental management. Geographic information system (GIS) was the main enabling technological approach for the integration of the multi-dimensional data sets used in the study.

\section{Study area}

\section{Materials and methods}

The New Juaben District and parts of the neighbouring districts investigated are delimited by latitudes $0^{\circ} 10^{\prime} \mathrm{W}$ and $0^{\circ} 24^{\prime} \mathrm{W}$, and longitudes $5^{\circ} 55^{\prime} \mathrm{N}$ and $6^{\circ} 15^{\prime} \mathrm{N}$ (Fig. 1). Though the New Juaben District was the primary focus of the study, sections of the neighbouring districts that interface directly with the New Juaben District were considered in the remote sensing and GIS studies. The mean temperatures are approximately $27^{\circ} \mathrm{C}$, occurring from February to March, and 26 ${ }^{\circ} \mathrm{C}$ from July to August (Dickson \& Benneh, 1988). Rainfall regime is bi-modal, with a mean annual rainfall range of between 1200-1700 mm. From December to February, the area comes under the influence of the Harmattan winds that precipitate the onset of the dry season.

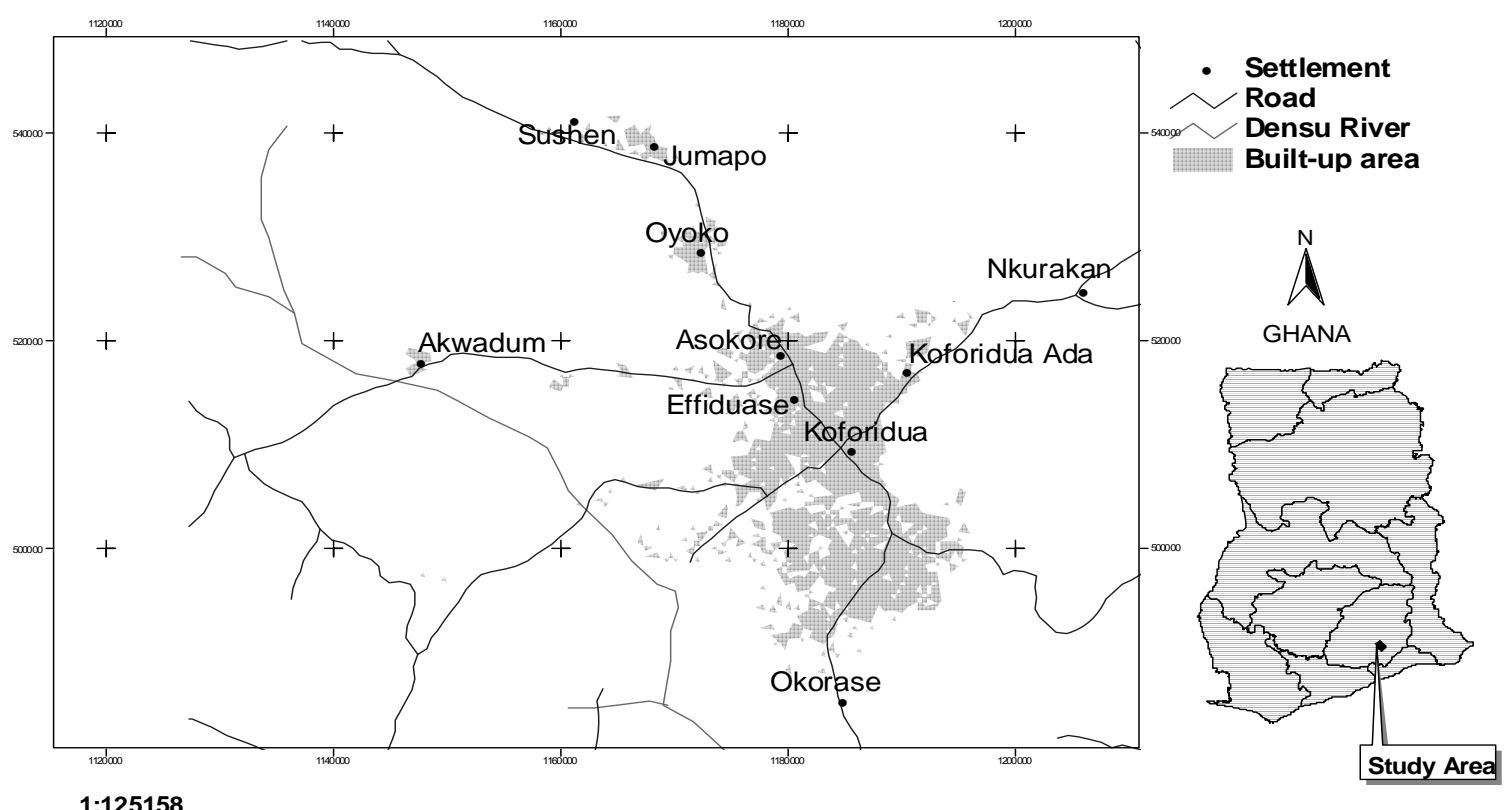

Fig 1 Location of the study area

The major soils of the area are Nankese-Koforidua/Nta-Ofin, Adawso-Bawjiasi Assciaction and Fete-Bediesi Complex associations. Nankese-Koforidua/Nta-Ofin occurs on undulating topography with a slope range of $5-12 \%$. It has moderate to severe susceptibility to erosion and maintains fairly high moisture retention capacity. It is suitable for a wide range of tree and arable crops, and highly suitable for cocoa. The Adawso-Bawjiasi Assciaction is moderately or imperfectly drained, susceptible to drought, and more so to erosion. They support maize, cassava, yams, pineapples, etc. Permanent crops such as citrus and mangoes are also suitable. It has moderate suitability for cocoa production. The Fete-Bediesi Complex is a mixture of good and bad soils. The good lands occur on 
slopes, with soils that are moderately or imperfectly drained. This area is considered suitable for tree and arable crops. It has a medium productivity rating for cocoa under medium agriculture input (Adu \& Asiamah, 1992).

Though the area is classified as semi-deciduous forest, the progressively intense land-use pressure has reduced the original pristine forest vegetation to isolated patches of forest formations that occur in the most inaccessible areas such as summits of highlands. Large tracts of land are covered with food crops and fallows at various stages of maturity. Generally, the area supports the cultivation of cocoa, kola, oil palm and other tree crops.

\section{Mapping of native trees, cocoa and fallow cover}

The fieldwork was conducted between December 2001 and March 2002. This was to ensure a fair correspondence between the ground-thruthing information and that generated from the satellite data. One hundred and fifty (150) quadrats of $30 \mathrm{~m} \times 30 \mathrm{~m}$ were randomly placed and georeferenced with a 12XL Gamin GPS receiver. At each site, the vegetation and the cropping systems were recorded. Native trees with a diameter of $10.0 \mathrm{~cm}$ or more, at breast height $(1.3 \mathrm{~m})$ were also counted in the quadrats. The presence or absence of fallow fields and/or annual crops were recorded. Cocoa trees in each quadrat were counted. Cocoa tree surface was generated from the cocoa tree counts using Arcview 3.2 software.

\section{Satellite data processing, classification, verification and accuracy}

Landsat Enhanced Thematic Mapper (Landsat ETM+) satellite data capture in December 2000 was acquired for the study. The images were geometrically corrected by registering them to a digital topographic map of Ghana with a scale of 1:50,000. Sixteen ground control points (GCPs) were collected for the registration process. The second power deformation model was used for the registration. Besides producing a more accurate result, it does not distort the resultant image (Jensen, 1996).

Bands 3, 4 and 5 were loaded to the red-green-blue (RGB) in the order of 5,4 and 3, respectively. A contrast-stretch enhance-ment was applied to optimize information interpretation and extraction from the false colour composite. This was appropriately used since the spectral distribution was Gaussian in nature (Jensen, 1996). In the enhanced image, thicker forest vegetation appeared dark green, with open forest formation appearing light green. Young or short fallows/annual crops appeared greenish yellow or yellow, with built-up/exposed or bare ground appearing reddish and purple, respectively.

Five or six carefully selected representa-tive training sites represented each identified landuse/cover types. These were used to train the classification algorithm. Based on field information, a simple hybrid of functional-structural land-use/cover classifi-cation scheme consisting of five categories was designed. The Maximum Likelihood supervise classifier algorithm technique was used to classify the composite into the five land-use/cover categories, namely 1 . Built-up/exposed (exp): constructed features such as buildings and roads and bare grounds; 2. Forest-farms (forfarm): patches of dense forest or a mixture of cocoa farms and forest formations; 3. Long fallow (longfall): dense and high thicket with young or medium sized trees; 4. Short fallow (shfall)/annual crop farms (anncrop): young fallows or annual food-crop farms or a mixture of both, usually with widely spaced isolated trees; 5 . Degraded lands (deg): comparatively short vegetation of grass and other herbs invariably associated with highlands with a history of permanent intensive cultivation and frequent bush burning.

The importance accorded the vegetated classes, and the appreciable level of within cover variability necessitated the use of relatively high number of test samples. A total of 180 test samples were randomly collected from the various land-use categories and characterized. The pixels used to train the Maximum Likelihood algorithm were not used as test samples. This was to ensure that the reference information was as independent or unbiased as possible. The test sample point shape was rasterised and used for a pixel-by-pixel comparison with the classified image, and accuracy West African Journal of Applied Ecology, vol. 14, 2008 
computed using Kappa statistical technique (Carstensen, 1987). An accuracy of 89.8\% was accepted for the study.

\section{Soils}

Digital maps of soil association and suitability at a scale of 1: 250,000 (Fig. 2) were used. The three most extensively occurring soil types and suitability categories were considered in the study. These are Nankese-Koforidua/Nta-Ofin, Adawso-Bawjiasi and Fete-Bediesi Complex associations.

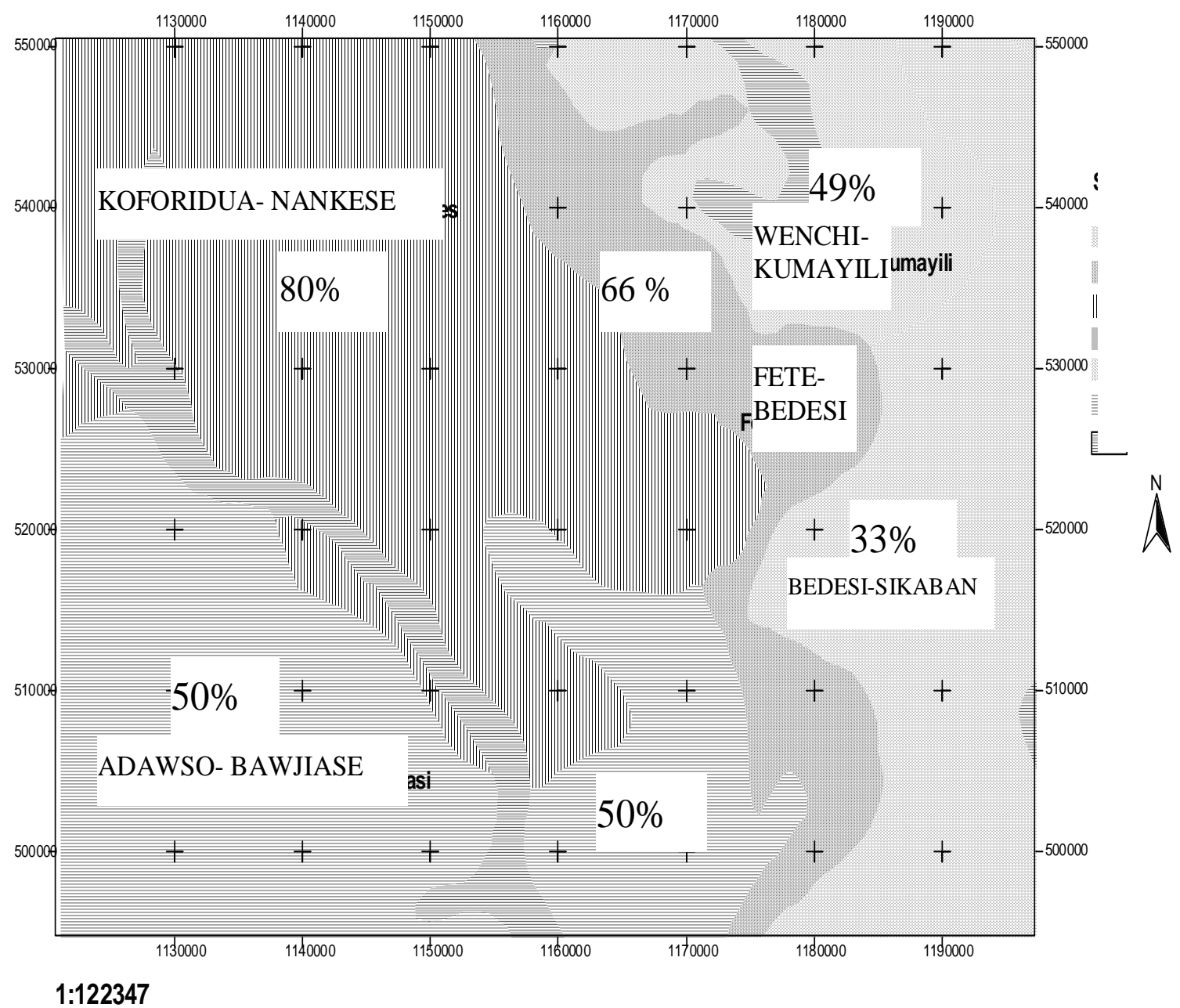

Fig. 2. Percentage cocoa productivity of soil types under medium input level in the study area

\section{Data analysis}

The satellite bands and the number of trees were used as predictor variables to assign the vegetation-crop samples to pre-determined groups at three levels of cocoa tree densities using discriminant function analysis (DA) (Manly, 1992). The groups were 1) cocoa farms with normal tree densities (normal cocoa farms), 2) those that have been partially converted into fallow and annual crops (moderate conversion), and 3) those with only remnant cocoa trees, or totally converted into fallow and annual food crops (total/extreme conversion). In the case of the last group, farmers were asked of the history of cropping systems on their farmlands. These were displayed in a canonical plot of the first two canonical functions.

The same analysis was carried out using the Landsat ETM+ (2000) bands, but substituting the density of cocoa trees for the number of indigenous trees as predictor variables. The samples were then assigned to categories or levels of deforestation. The first two functions were used to display 
the samples. The GIS analyses were carried out in ArcView 3.2 and IDRISI Kilimanjaro, in a grid format since it is computationally easier and faster for overlay analyses (Martin, 1996).

\section{Results}

Tree abundance distribution and fallow formation

There were a total of 618 trees in all the 150 quadrats (13.5 ha), which constituted an average of 48 trees per ha. The abundance-class distribution plot (Fig. 3) was positively skewed, presupposing a high degree of rarity. There was a mean of four native trees per quadrat. A significant inverse relationship (ETA $=0.294, P<0.01$ ) existed between the tree density and fallow occurrence. That is, low tree densities largely occurred where fallow dominated.

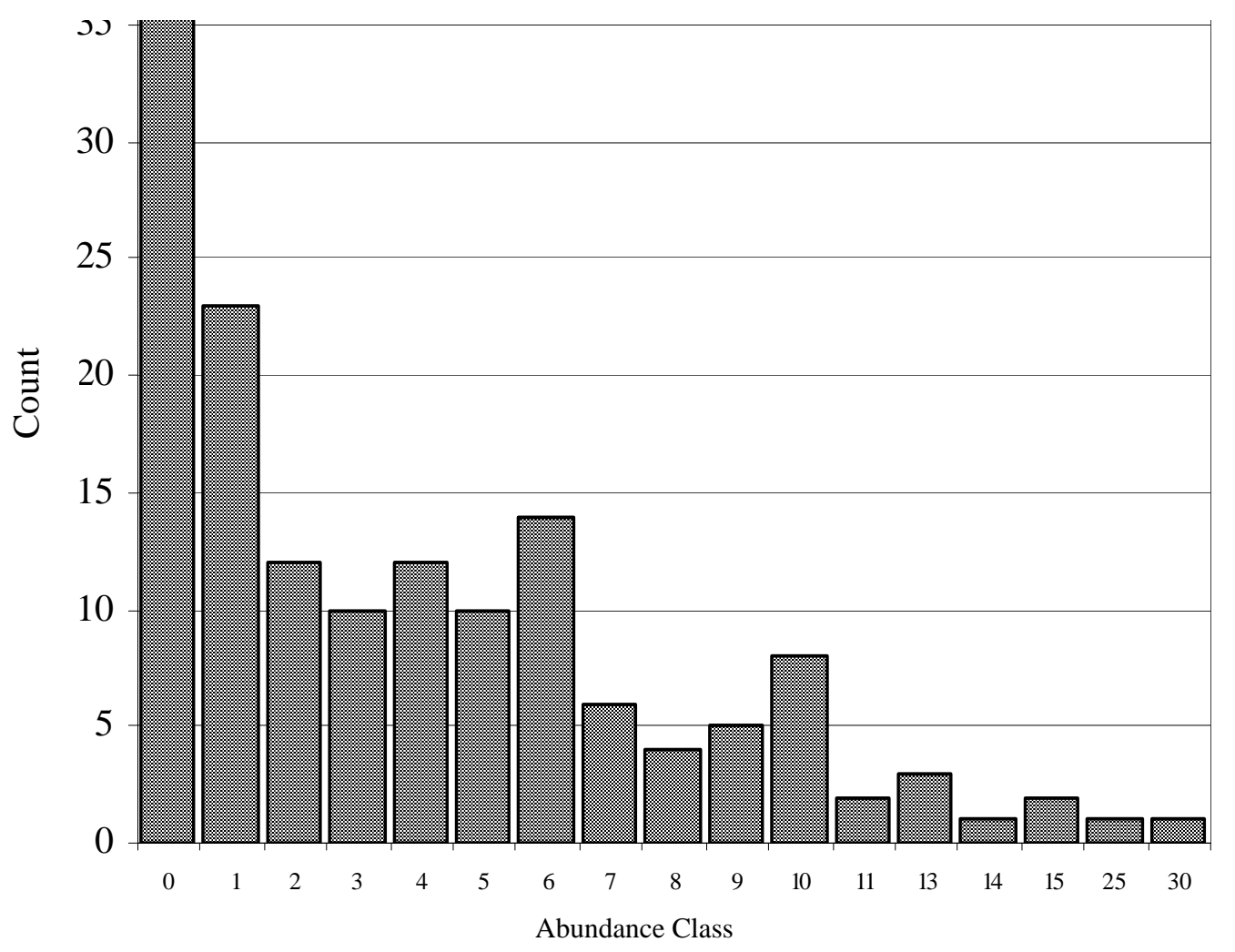

Fig. 3. Abundance tree-class distribution

The first discriminant function (1) was a measure of the amount of tree cover; it contributed $99.2 \%$ of the total explained variance among the samples. It predicted group memberships of the samples for the three levels of deforestation categories: no/incipient, moderate and total/extreme to different extent (Fig. 4). The first function separated the centriods of the three groups of deforestation more than the second function. Wilks' lambda $(\Lambda)$ test confirmed the first canonical function as capable of significantly $(P<0.01)$ discriminating between the means of the three broad tree densities. There was, however, a considerable overlap between the moderate and the normal tree density categories (Fig. 4). 


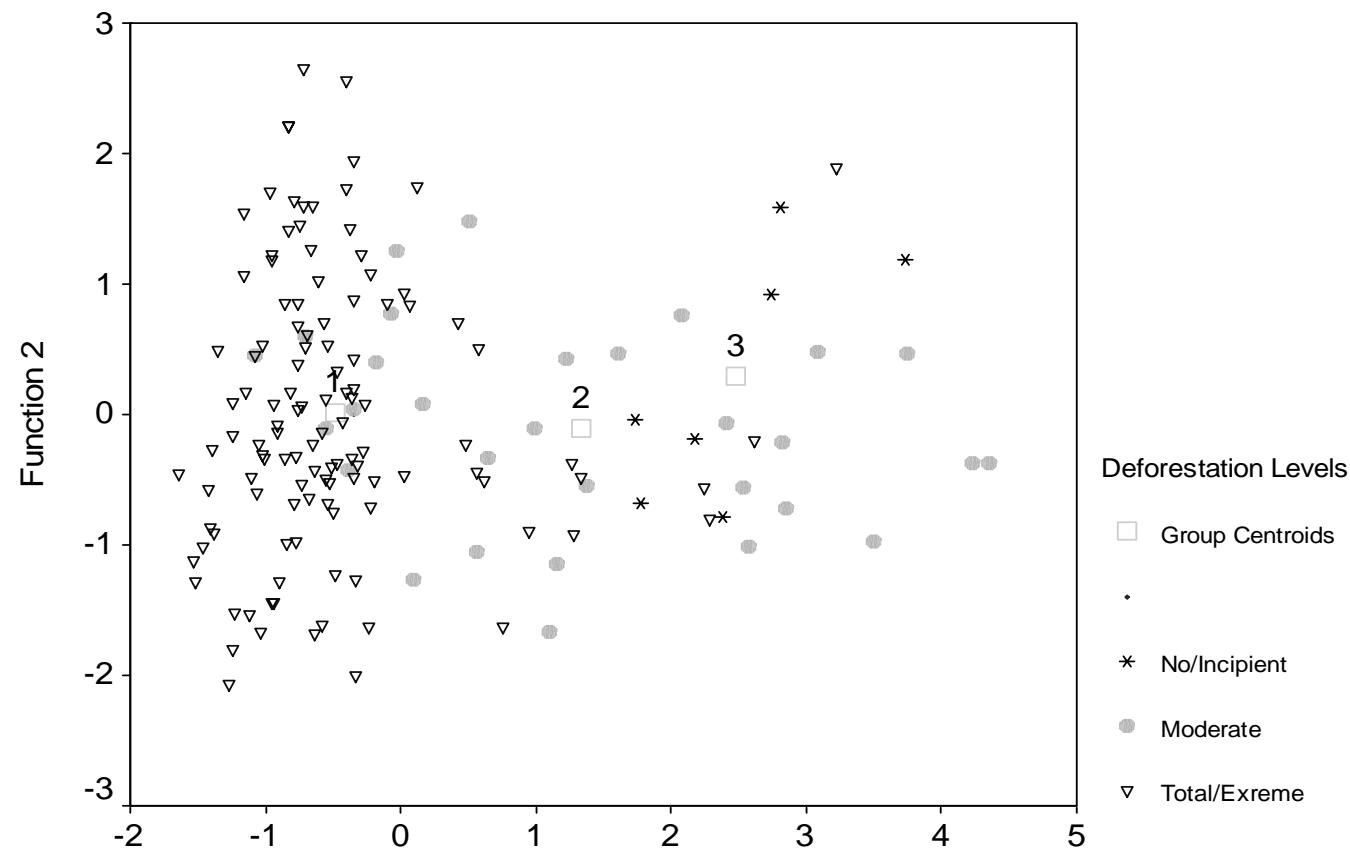

Fig. 4. Deforestation group membership of the samples

$$
\begin{aligned}
& F i=0.936 C-0.460 b 5-0.452 b 3-0.420 b 2-0.382 b 7+0.130 b 4 \\
& F i i=-120 C+0.262 b 5+0.096 b 3+0.691 b 2+0430 b 7+0.190 b 4
\end{aligned}
$$

\section{Cocoa tree abundance}

There were 2,527 cocoa trees in the 150 quadrats, with a mean of 19 cocoa trees per quadrat. This was equivalent to 133 cocoa trees per ha. They were distributed with a wide spatial variability. The abundance distribution was heavily skewed towards the least abundance classes, with $58.0 \%$ of the quadrats recording zero (0) cocoa trees and $65.3 \%$ of the quadrats containing $0-5$ numbers of cocoa trees. This may indicate a conversion of cocoa farms into either fallow or annual crop farms.

\section{Relationship between cocoa and indigenous trees}

There was a high positive relationship between the number of indigenous trees and cocoa tree density (Fig. 5). The association was highly significant $(P<0.01)$. The uncertainty coefficient indicated that tree density was a highly significant $(P<0.01)$ predictor of cocoa density in the area. The discriminant function analysis of the satellite bands and tree densities generated two canonical functions that predicted group memberships for the sites, and discriminated between the three levels of cocoa farm conversions (Fig. 6). The eigenvalues of the first and the second functions were $0.786(86.1 \%)$ and $0.127(13.9 \%)$. The Wilks' lambda test indicated that the means of the conversion classes were significantly $(P<0.01)$ different for the two discriminant functions. 


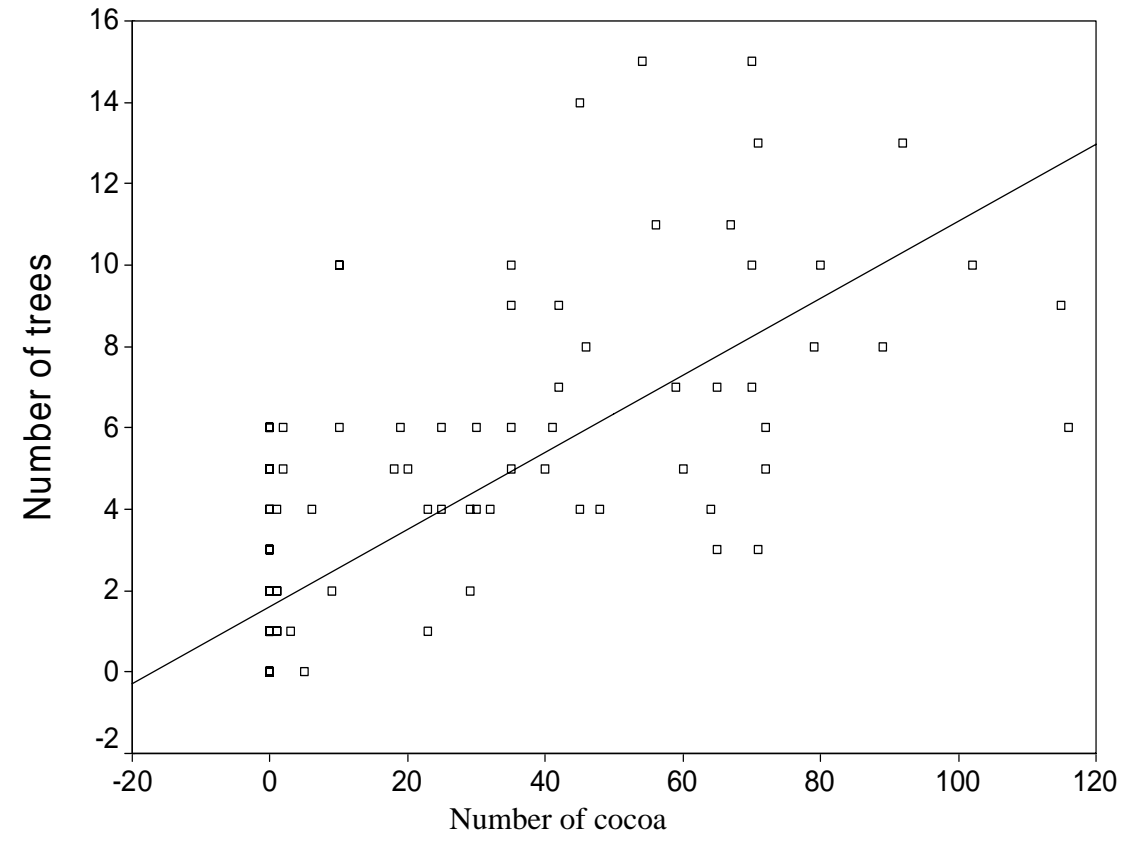

Fig. 5. Association between cocoa and tree numbers

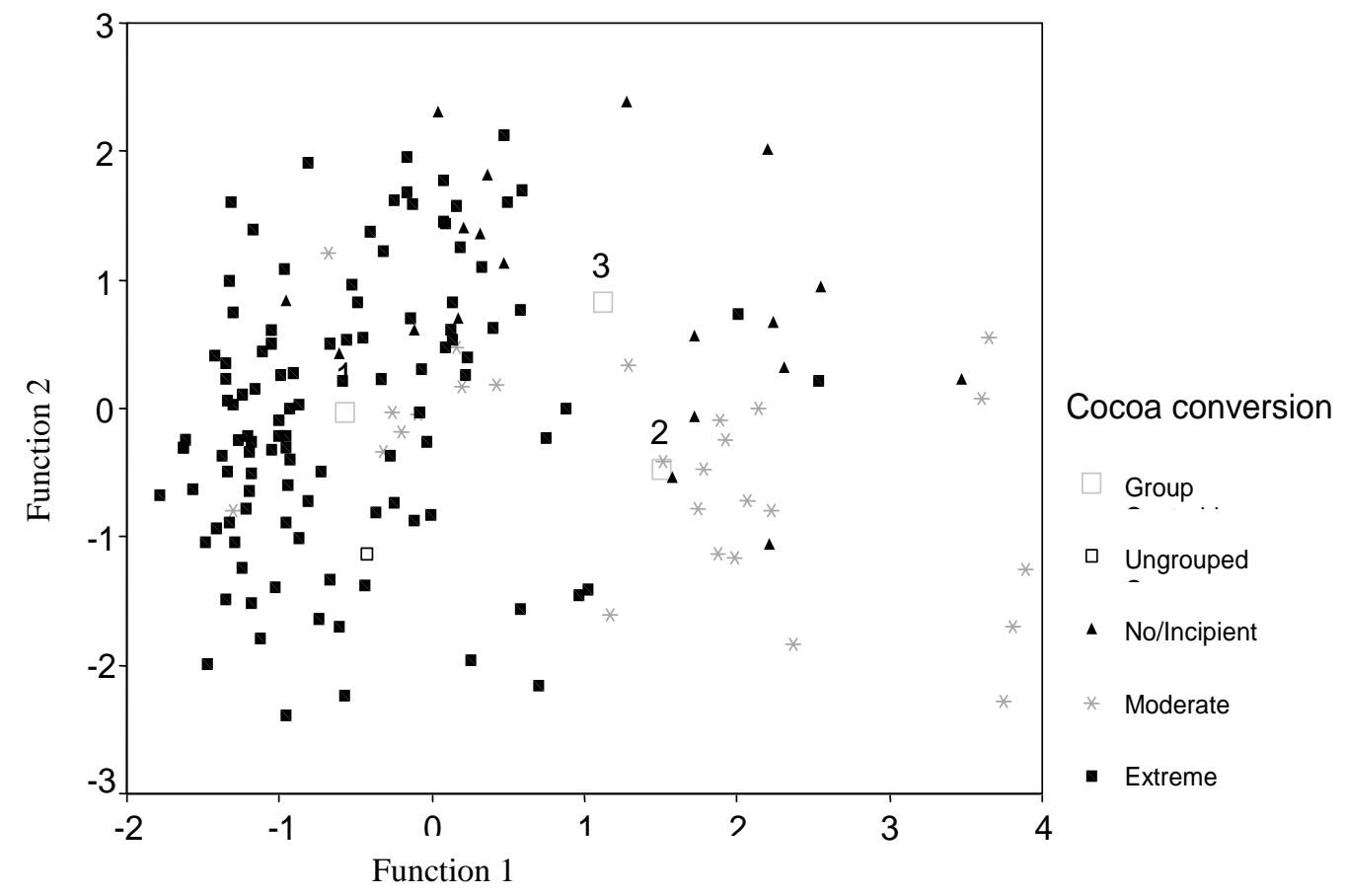

Fig. 6. Separation of conversion group members of cocoa samples

Fig. 7 represents the cocoa density surface, with Fig. 8 being the classified satellite landuse/cover imagery of the area. A strong spatial association existed between the soil types (Fig. 2), the prevailing spatial distribution of cocoa farms (Fig. 7) and the classified land-use/cover. Nankese-Koforidua Associations, which is classified as the most suitable soil for cocoa production, was extensively covered with cocoa farms (Fig. 7, 8 and 9). 


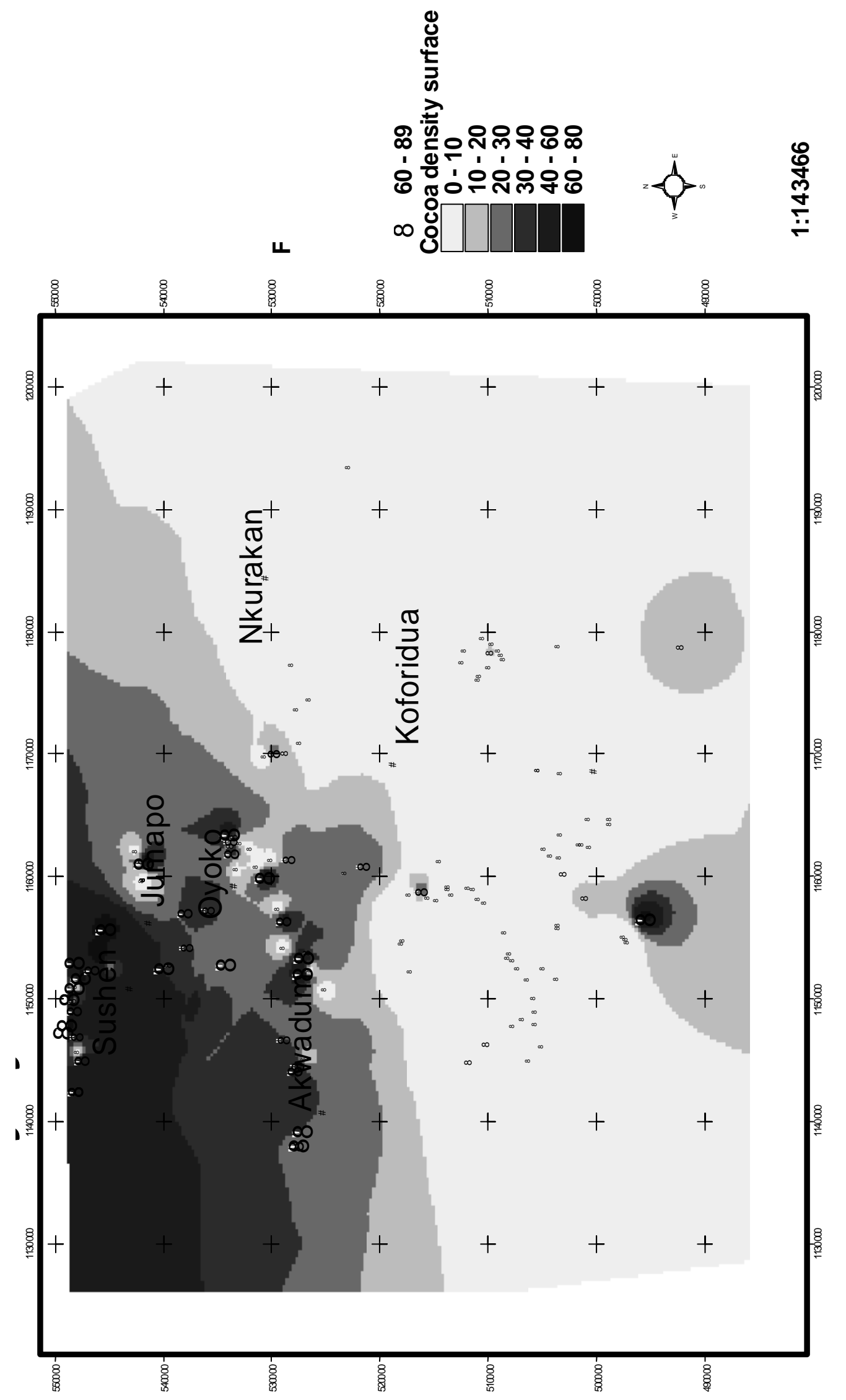

Fig. 7. Cocoa density surface. High density was found in suitable soils. 


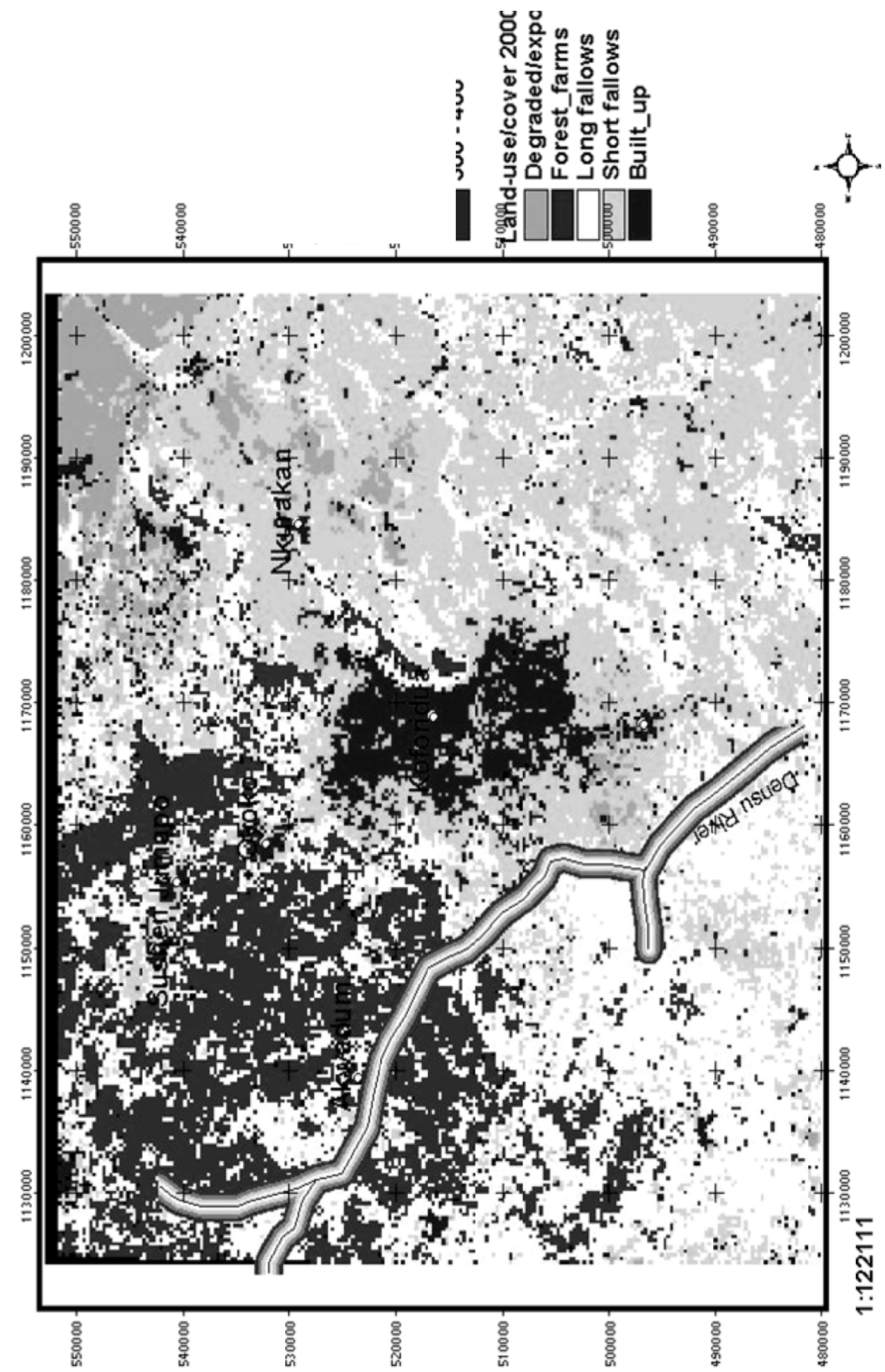

Fig. 8. Land-use/cover of Landsat ETM 2000. Forest vegetation is concentrated to the left where cocoa and good soils are currently found. 


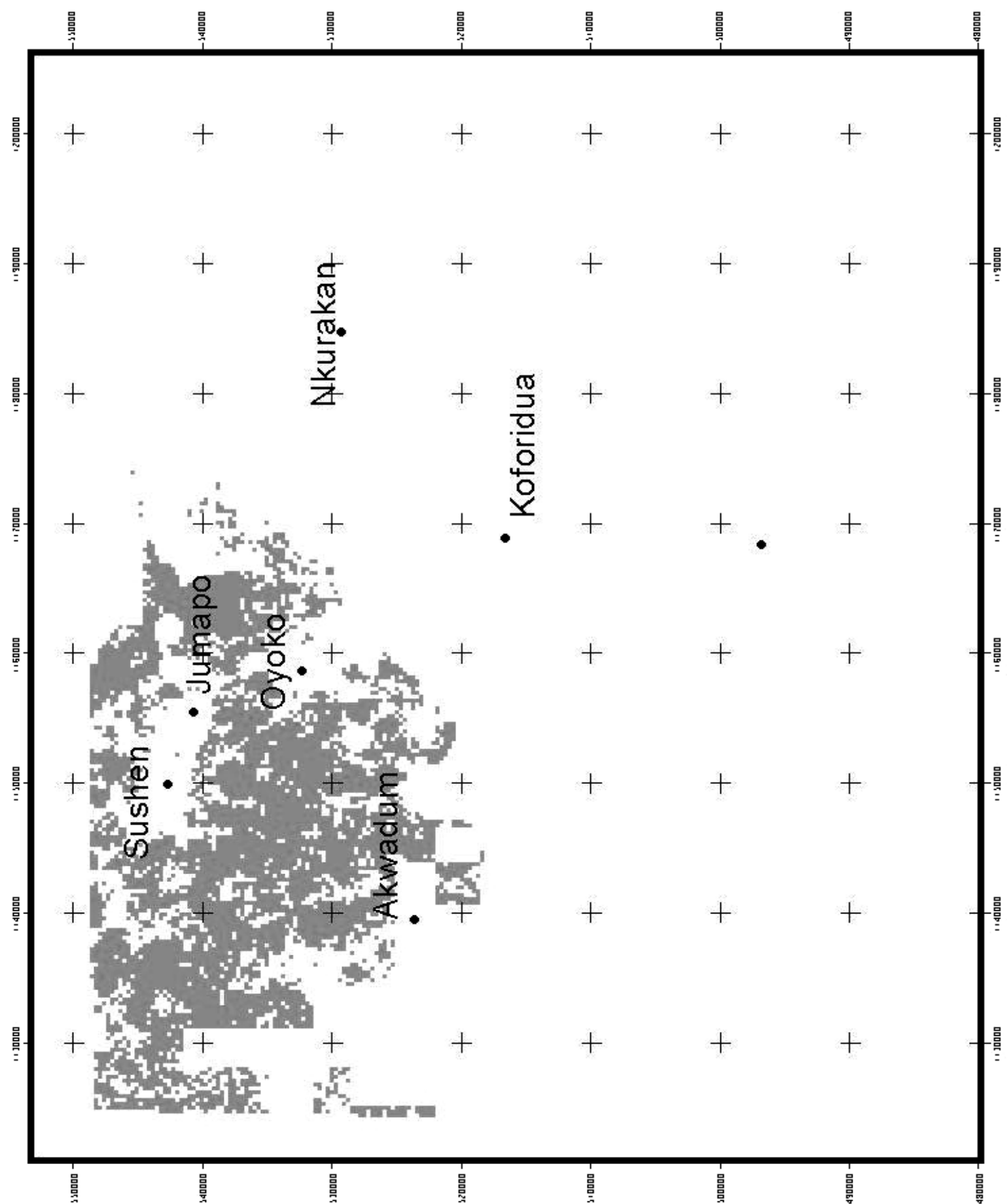

Fig. 9. Location of high level of sustainable cocoa production. This was found in areas with suitable soils and high tree densities. 


\section{Discussion}

Studies have confirmed the pattern of strong association between the density of trees and cocoa formations in Ghana (Attua \& Laing, 2003, 2005). In the traditional system of farming, trees are usually left on cocoa farms to provide humid conditions, shade and protection, especially to young cocoa plants. This has become the conventional farm management system for cocoa cultivation in the area. Therefore, matured fallow or vegetation formations with trees are normally perceived as most suitable land types for cocoa cultivation in Ghana. This may explain why cocoa was found in association with high tree numbers, but in reduced numbers in fallows.

Reduction in percentage of tree cover may threaten the sustainability of cocoa production by modifying the general biophysical conditions necessary for their existence (Amanor, 1994). It may undermine land suitability potential to support the production of tree crops such as cocoa that need some amount of tree cover for establishment and protection. The outcome of this study supports this claim since cocoa farms were generally confined to areas of high tree density (Pabi, 1998).

Sustainable agriculture land-use requires that the natural productive potential of land resource base be maintained or enhanced, and to ensure that the ecological principle of resilience is achieved through the strict observance of complementarity (SCA, 1991). Evidently, some of the soils cultivated in the study area are naturally either marginally sustainable or unsuitable for cocoa. Soils such as Adawso-Bawjiasi/Nta-Ofin Association that were cultivated in the past are susceptible to drought and erosion (Adu \& Asiamah, 1992). According to some farmers, effort to re-cultivate these areas with cocoa has not been successful; the cocoa seedlings would wither and die as soon as the farms are replanted. This may be accounted for by the fact that this soil is susceptible to drought, with limited capacity to conserve moisture. This is a classical case of unsustainable cocoa production due to the cultivation of cocoa on unsuitable soils (Benneh, 1988).

Largely, the Koforidua-Nankese/Nta-Ofin association that is evaluated as good soils, with high soil moisture retention capacity, has continued to sustain a good number of cocoa farms. However, a simple causal relation between soil types and the distribution of cocoa farms is not being suggested, though, since important factors that are socio-economic and biophysical in nature could be operating in a complex fashion to influence growth, productivity, and even choice of cropping systems.

Obviously, cocoa production may be successful and ecologically sustainable in areas considered theoretically suitable. Yet, it is also true that successful production can be sustained provided there are high scientifically based agriculture inputs (Fearnside, 1987). This latter management regime, however, is currently lacking in the area. The implementation of the Economic Recovery Programme (ERP) in Ghana since the early 1980s has made it impossible for the country to continue supporting programmes of providing farmers with cheap subsidized agriculture inputs that may ensure sustainable production of cocoa. On their own, poor and small scale cocoa farmers are normally unable to afford the cost involved. Hence, cultivating cocoa without adequate considerations to selecting lands that are naturally suitable are bound to be unsustainable.

\section{Conclusion}

From the study, it is obvious that it has not been a standard or normal practice for farmers to be educated on identification of suitable soils for newly introduced crops. At the time of introducing cocoa in the study area, it is apparent that farmers had no previous experience of the long-term performance and related environmental impacts of cocoa on various land types. Most farmers may have assumed that all forested lands were suitable for cocoa production. They may have ignored the fact that different soils support cocoa production to different extent.

Soils as a factor appear to have a higher weight in sustainable cocoa production equation. Even though tree cover is also important, it appears to have a relatively subsidiary influence to soils for sustainable cocoa production. The synergistic influence of soils and trees on sustainable cocoa 
production could be more important than the two factors operating in isolation. Since farmers can no longer afford the cost of agriculture input, it is only reasonable for farmers to identify soils that are naturally good for sustainable cocoa production. This will ensure sustainable cocoa production, and the protection of cocoa-tree-land ecosystems from degradation.

\section{References}

Adu S. V. and Asiamah R. D. (1992). Soil of the Ayensu and Densu Basin; Central, Eastern Regions, Ghana. Soils Research Institute, Accra.

Amanor K. S. (1994). The new frontiers. Response to land degradation. A West African study. ZED Books Limited, London and New Jersey.

Attua E. M. and Laing E. (2003). Agriculture land-use impacts on the flora of the Densu Basin. Ghana Sci. Ass. J. 5: 77 83.

Attua E. M. and Laing E. (2005). Ecological assessment of carbon sequestration and partitioning in regenerating fallow. Ghana Sci. Ass. J. 7: 123-133.

Attua E. M. (1996). Agricultural land use and cover change. A case study in the mid-Densu Basin. (M Phil. Thesis.). Department of Botany, University of Ghana. Accra.

Benneh G. (1988). The New cocoa frontiers of Ghana. In Agriculture expansion and pioneer settlements. (W. Manshard and W. B. Morgan, ed.) United Nations University, Hong Kong.

Blackwell S. (2007)/ Cocoa: West Africa. Afr. Res. Bull. 44: 17419-17420.

Carstensen L. W. (1987). A measurement of similarity for cellular maps. The American Cartographer 14 (4): 345-358.

Dickson K. B. and Benneh G (1988). A new geography of Ghana. Longman, London.

Fasina Omotoso O., Shittu S and Adenikinju A. P. (2007). Properties, classification and suitability evaluation of some selected cocoa soils of South-Western Nigeria, American-Eurasian J. Agric. Envir. Sci. 2: 312-317.

Fearnside P. M. (1987b)/ Deforestation and international economic development project in Brazil Amazonia. Conserv. Biol. 1: 214-221.

Francis C. and Youngberg G. (1990). Sustainable Agriculture - An Overview. In Sustainable Agriculture in Temperate Zones. (C. A. Francis, C. B. Flora, and L. D. King, ed.) Wiley, New York.

Jensen J. R. (1996). Introductory digital image processing; a remote sensing perspective, 2nd edn. Prentice Hall, New Jersey.

Jensen J. R., Narumalani S., Weatherbee O. and Mackey H. E. (1993). Measurement of seasonal yearly cattail and waterlily distribution using remote sensing and GIS Techniques. Photogram. Engng Rem. Sen. 59: 519-525.

Manly B. F. J.(1992). Mutivariate statistical methods, A primer. Champman and Hall, London.

Martin D. J. (1996). Geographic information systems; socioeconomic applications, 2nd edn. Routledge, London.

Pabi O. (1998). Land use effects on ecosystems near Koforidua (MPhil. Thesis.), Department of Geography and Resource Development, University of Ghana, Accra.

SCA (1991). Sustainable Agriculture. Standing Committee on Agriculture Technical Report Series, No. 36. Report of the Workshop Group on Sustainable Agriculture, SCA, East Melbourne. Council for Scientific and Industrial Research, Melbourne.

Smyth A. J. and Dumanski J. (1993). FESLM: An international framework for evaluating sustainable land management. A discussion paper. World Soil Resources Report 73. FAO, Rome. 